\title{
Observations on the Structure of Bacilysin
}

\author{
BY HENRY J. ROGERS,* NINA LOMAKINA † AND E. P. ABRAHAM \\ Sir William Dunn School of Pathology, University of Oxford
}

(Received 2 April 1965)

\begin{abstract}
1. Elementary analysis and other properties of a highly purified preparation of bacilysin indicated that a possible molecular formula for the substance is $\mathrm{C}_{12} \mathrm{H}_{18} \mathrm{~N}_{2} \mathrm{O}_{5}$. The results of electrometric titration were consistent with the hypothesis that the substance was a peptide containing one free $\alpha$-amino group and one free carboxyl group. 2. Hydrolysis of bacilysin with $6 \mathrm{~N}$-hydrochloric acid at $105^{\circ}$ yielded L-alanine and L-tyrosine, but the ultraviolet spectrum of the substance showed that no tyrosine residue was present in the molecule and a nuclear-magnetic-resonance spectrum indicated that olefinic and aromatic protons were absent. The dinitrophenyl (DNP) derivative of bacilysin yielded DNPalanine on acid hydrolysis. 3. Bacilysin was hydrolysed by leucine aminopeptidase (EC 3.4.1.1) and by Pronase to give alanine and an uncharacterized amino acid. Its infrared spectrum was consistent with the presence of a peptide grouping in the molecule. 4. The optical rotatory dispersion of bacilysin and its reaction with thiosemicarbazide indicated that the substance contained an aldehyde or ketone group. Its behaviour on catalytic reduction and its reaction with sodium thiosulphate and with certain thiols suggested that an epoxide group was present. 5. A possible type of structure for bacilysin is considered in the light of its known properties.
\end{abstract}

A purified preparation of bacilysin (Rogers, Newton \& Abraham, 1965) contained $\mathrm{C}, \mathrm{H}$ and $\mathrm{N}$, but no $\mathrm{Cl}$ and only traces of $\mathrm{S}$. A possible empirical formula was $\mathrm{C}_{12} \mathrm{H}_{18} \mathrm{~N}_{2} \mathrm{O}_{5}$ (mol.wt. 270). The substance was optically active, having $[\alpha]_{\mathrm{D}}^{20}+103^{\circ}$ (c 0.643 in water). It showed no selective absorption in ultraviolet light above $220 \mathrm{~m} \mu$. Electrometric titration showed the presence of groups with $\mathrm{p} K_{a} 3.0$ and $\mathrm{p} K_{a} 8.2$ respectively and gave an equivalent of $280 \pm 15$ (Fig. 1). A broad band at $3300 \mathrm{~cm} .^{-1}$ and bands at $3080,1670,1600,1525$ and $1390 \mathrm{~cm} .^{-1}$ were observed in its infrared spectrum. These properties, in conjunction with the fact that the product showed a positive ninhydrin reaction, were consistent with the view that bacilysin is a dipeptide. In the following discussion its molecular weight has been assumed to be 270 .

Hydrolysis of bacilysin with $6 \mathrm{~N}$-hydrochloric acid at $105^{\circ}$ for $24 \mathrm{hr}$. yielded two ninhydrinpositive compounds, which behaved like alanine and tyrosine respectively on paper chromatography and electrophoresis (Fig. 2). The ultraviolet spectrum of the material obtained on evaporation of

* Present address: The Rowett Research Institute, Bucksburn, Aberdeen.

$\dagger$ Present address: The Institute of New Antibiotics, Moscow, U.S.S.R. the hydrolysate corresponded closely to that of tyrosine, showing $\lambda_{\max .} 275 \mathrm{~m} \mu$ in water and $\lambda_{\max }$. $292 \mathrm{~m} \mu$ in $0.1 \mathrm{~N}$-sodium hydroxide. Quantitative estimations with an amino acid analyser indicated that $1 \mathrm{~mol}$. of alanine, $0.78 \mathrm{~mol}$. of tyrosine and

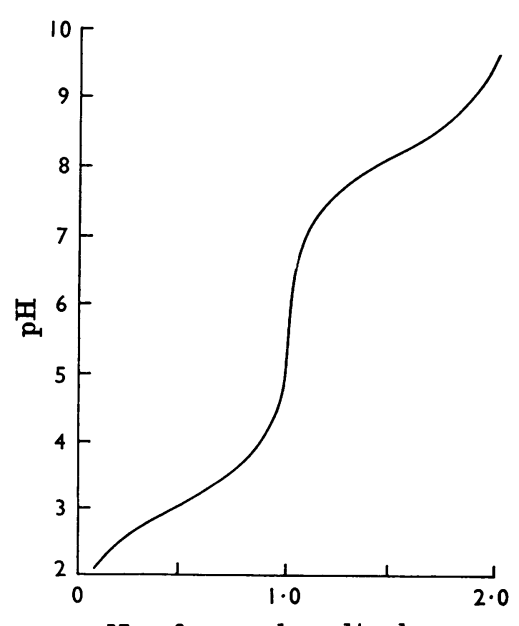

No. of groups bound/mol.

Fig. 1. Electrometric titration of bacilysin in water. 
$0.06 \mathrm{~mol}$. of ammonia had been formed from $1 \mathrm{~mol}$. of bacilysin on hydrolysis. A nuclear-magneticresonance (n.m.r.) spectrum of the substance in $\mathrm{D}_{2} \mathrm{O}$ showed a doublet at 8.40 and 8.50p.p.m. ( $\tau$ scale), which could be attributed to the $\mathrm{CH}_{3}$ of an alanine residue. However, the failure of bacilysin to show a band near $280 \mathrm{~m} \mu$ in its ultraviolet spectrum and to couple with diazotized sulphanilic acid indicated that it did not contain a tyrosine residue. The absence of any signal in the range 1.0-4.0p.p.m. of the n.m.r. spectrum indicated that no aromatic protons were present in the molecule.

In addition to tyrosine an amino acid with $R_{F}$ 0.25 in butan-1-ol-acetic acid-water was found in trace amounts in the hydrolysate. This gave a grey colour with ninhydrin and reacted with diazotized sulphanilic acid and with the ferric chloride-potassium ferricyanide reagent (Kirby, Knowles \& White, 1953). In the amino acid analyser it emerged from the column between 3,4-dihydroxyphenylalanine and tyrosine. It may therefore be one of the dihydroxyphenylalanines.

Bacilysin reacted with $0.97 \mathrm{~mol}$. of 1-fluoro-2,4dinitrobenzene $/ \mathrm{mol}$. at $\mathrm{pH} 9 \cdot 0$, the reaction being followed either spectrophotometrically or in a $\mathrm{pH}$ stat. The DNP derivative ran as a single band when chromatographed on Sephadex G-25 in $N$ ethylmorpholinium acetate, $\mathrm{pH} 7 \cdot 0$, and when subjected to electrophoresis at $\mathrm{pH} 4.5(80 \mathrm{v} / \mathrm{cm}$. for $20 \mathrm{~min}$.) it migrated $5.5 \mathrm{~cm}$. towards the anode. It showed less than $10 \%$ of the antibacterial activity of bacilysin itself. When the reaction with fluorodinitrobenzene was terminated before it had reached completion only a spot due to unchanged bacilysin and a single spot near the origin, due to a DNP derivative, were detected after electrophoresis on paper at $\mathrm{pH} 1 \cdot 8$. This was consistent with the presence of a single $N$-terminal amino acid in the molecule.

Hydrolysis of DNP-bacilysin with $6 \mathrm{~N}$-hydrochloric acid at $105^{\circ}$ yielded tyrosine and an ethersoluble DNP-amino acid that was indistinguishable from DNP-alanine when subjected to chromatography on paper (Fraenkel-Conrat, Harris \& Levy, 1955). On hydrolysis with aq. ammonia (sp.gr. 0.88) (Lowther, 1951) the DNP-amino acid yielded a substance that behaved like alanine on paper chromatography and electrophoresis.

These results indicated that bacilysin contained a single $N$-terminal alanine residue. Further experiments were carried out with a sample (5 mg.) of bacilysin to determine the optical configurations of the alanine residue and of the tyrosine formed on hydrolysis with $6 \mathrm{~N}-\mathrm{hydrochloric}$ acid at $105^{\circ}$. Alanine and tyrosine in the hydrolysate were separated by chromatography on Dowex 1 (X8) in $0.5 \mathrm{~N}$-acetic acid. Under these conditions alanine passed through the column with the solvent front and was completely resolved from tyrosine, which was eluted later (Hirs, Moore \& Stein, 1954). A qualitative indication of the configuration of the alanine was obtained by the method of Wagner (1960). Samples (each about $15 \mu \mathrm{g}$.) of the product, together with controls of authentic $D$ - and L-alanine, were spotted on to paper. The papers were sprayed with solutions of $\mathbf{D}$-amino acid oxidase and L-amino acid oxidase respectively and hung in a moist atmosphere at $37^{\circ}$ for $2 \mathrm{hr}$. A spray of $o$-phenylenediamine $(0.1 \%, w / v)$ in aq. trichloroacetic acid $(10 \%, w / v)$ was then used to detect the formation of pyruvate, which gave a strongly green-fluorescent spot when the paper was viewed under ultraviolet light after heating for $3 \mathrm{~min}$. at $100^{\circ}$. The results obtained by this procedure with both enzymes showed that the alanine from bacilysin was mainly, at least, the L-isomer. However, in control experiments this procedure did not prove to be satisfactory for estimation of the optical configuration of tyrosine. A second procedure involved

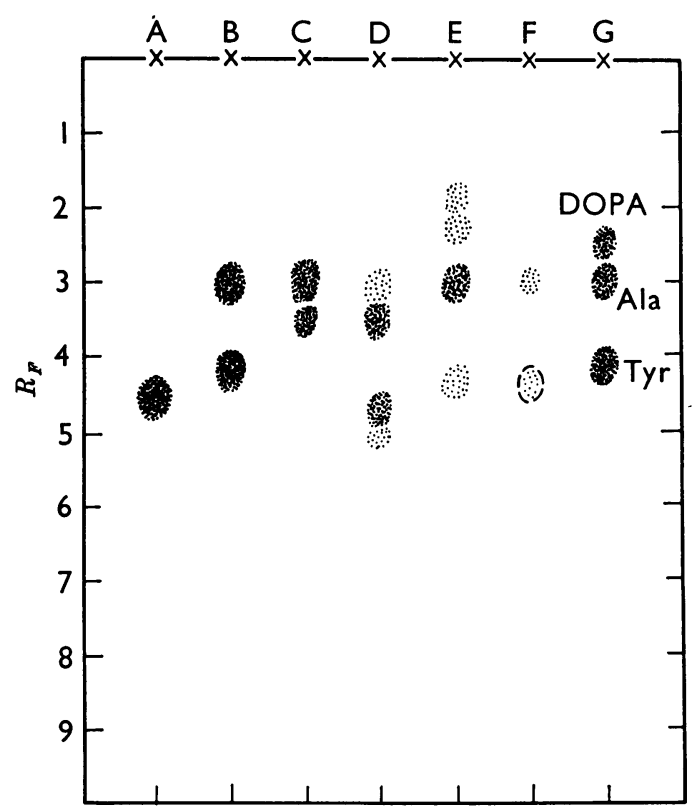

Fig. 2. Chromatography on paper in butan-1-ol-acetic acid-water of: A, bacilysin; $B$, hydrolysate of bacilysin with $6 \mathrm{~N}-\mathrm{HCl}$ at $105^{\circ} ; \mathrm{C}$, products of hydrolysis with leucine aminopeptidase; $\mathrm{D}$, products of hydrogenation with $\mathrm{PtO}_{2}$ catalyst; $\mathrm{E}$, hydrolysate of products of hydrogenation; $\mathrm{F}$, products of hydrolysis of bacilysin with $2 \mathrm{~N}-\mathrm{HCl}$ at $105^{\circ}$ for $1 \mathrm{hr}$.; G, 3,4-dihydroxyphenylalanine (DOPA), alanine and tyrosine. All the substances showed no net charge on electrophoresis at pH4.5. The depth of shading indicates the approximate intensity of the spots after coloration with ninhydrin. The spot outlined with a broken line absorbed ultraviolet light. 
treatment of the alanine and tyrosine (each about $30 \mu \mathrm{g}$.) from bacilysin with D-and L-amino acid oxidase respectively in aqueous solution and determination of the ammonia liberated with Nessler's reagent. The results showed that both the alanine and tyrosine had the L-configuration.

Further support for the view that bacilysin was a dipeptide containing L-amino acid residues was obtained by the use of leucine aminopeptidase (EC 3.4.1.1) from hog kidney and also of Pronase, a mixture of proteases from Streptomyces griseus (Nomoto, Narahashi \& Murakami, 1960). Both enzyme preparations split bacilysin into alanine $\left(R_{F} 0 \cdot 30\right)$ and a second uncharacterized amino acid that showed $R_{F} 0.35$ and differed from tyrosine $\left(R_{F} 0 \cdot 42\right)$ when chromatographed on paper in butan1-ol-acetic acid-water (4:1:4, by vol.) (Fig. 2). The second amino acid showed no net charge at pH 4.5 and migrated towards the cathode slightly less far than bacilysin but further than tyrosine on electrophoresis at $\mathrm{pH} 1 \cdot 8$. The hydrolysis catalysed by leucine aminopeptidase was shown to be accompanied by loss of antibacterial activity.

Bacilysin thus appeared to be a dipeptide containing an $N$-terminal L-alanine residue and a residue of a new amino acid that was converted into $\mathrm{L}$ tyrosine by hot $6 \mathrm{~N}$-hydrochloric acid. A possible molecular formula for bacilysin $\left(\mathrm{C}_{12} \mathrm{H}_{18} \mathrm{~N}_{2} \mathrm{O}_{5}\right)$ differed from that of alanyltyrosine $\left(\mathrm{C}_{12} \mathrm{H}_{16} \mathrm{~N}_{2} \mathrm{O}_{4}\right)$ only in containing one more oxygen and two more hydrogen atoms, and no products other than alanine and tyrosine were detected in the acid hydrolysate after chromatography and electrophoresis on paper. Hence the key to the elucidation of the structure of bacilysin was presumably to be found in experiments designed to throw light on the nature of the tyrosine precursor.

The infrared spectrum of bacilysin showed a band at $1747 \mathrm{~cm}^{-1}$, which raised the question whether it contained a ring ketone. Two other properties of the substance indicated that it contained a carbonyl group. Its optical-rotatory-dispersion curve in water (kindly determined by Professor W. Klyne) showed a Cotton effect from 331 to $282 \mathrm{~m} \mu$, which clearly suggested that a ketone or aldehyde group was present, and a peak at $235 \mathrm{~m} \mu$, which might be due to peptide groupings (Fig. 3). When bacilysin reacted with thiosemicarbazide in sodium acetate buffer, $\mathrm{pH} 4.5$, at $20^{\circ}$ the solution showed a strong absorption band with $\lambda_{\max } 273 \mathrm{~m} \mu$ (Fig. 4). Strong absorption near $270 \mathrm{~m} \mu$ ( $\epsilon$ approx. $10^{4}$ ) is characteristic of the thiosemicarbazones of saturated aldehydes and ketones (Evans \& Gillam, 1943). After the reaction with thiosemicarbazide had proceeded for $1 \mathrm{hr}$. the extinction of the solution at $273 \mathrm{~m} \mu$ was similar to that which would have been expected if bacilysin had a molecular weight of 270 and had been con-

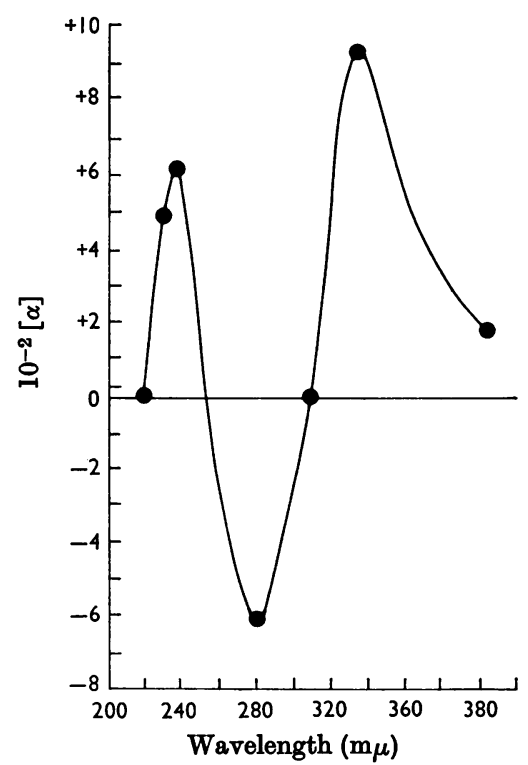

Fig. 3. Optical-rotatory-dispersion curve of bacilysin (208 units/mg.) in water.

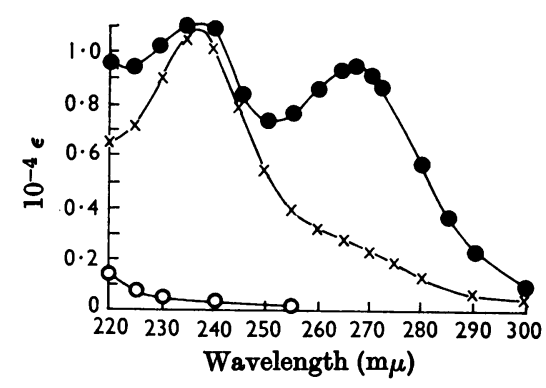

Fig. 4. Change in ultraviolet spectra after reaction of 0.1 mm-bacilysin (208 units/mg.) with $0.1 \mathrm{mm-thiosemi-}$ carbazide in aqueous solution for $\mathrm{lhr}$. $O$, Bacilysin before reaction; $x$, thiosemicarbazide; $\bullet$, reaction mixture.

verted into monosemicarbazone. It thus seemed that a six-membered-ring ketone might be present in the molecule and be the precursor of the $p$-hydroxyphenyl group of the tyrosine formed on vigorous hydrolysis with acid. An attempt was made to reduce the carbonyl group of bacilysin selectively with sodium borohydride in aqueous solution (see Brown, Mead \& Rao, 1955; Brown, Wheeler \& Ichikawa, 1957a,b; Brown \& Ichikawa, 1962); but analysis by paper chromatography and electrophoresis showed that the product was complex, containing at least three compounds with no net charge at $\mathrm{pH} 4 \cdot 5$. One of these compounds 
behaved like alanine, one showed an $R_{F}$ value close to that of tyrosine, and one showed $R_{\mathrm{Ala}} 0 \cdot 64$. After hydrolysis with $6 \mathrm{~N}$-hydrochloric acid at $105^{\circ}$ alanine was detected but there was no spot in a position corresponding to tyrosine.

The n.m.r. spectrum of bacilysin, which showed no signal between 2.0 and 4.8 p.p.m., indicated that olefinic hydrogen was not present in the molecule. However, hydrogenation of bacilysin at $25^{\circ}$ and atmospheric pressure, in the presence of either Adams platinum oxide catalyst or palladium on charcoal, resulted in an uptake of hydrogen that became slow after the first hour and reached approx. $1 \mathrm{~mol} . / \mathrm{mol}$. after $3 \mathrm{hr}$. The material recovered after hydrogenation did not show antistaphylococcal activity. With palladium on charcoal as a catalyst hydrogenation occurred without significant reduction of the carbonyl group, since the hydrogenated material reacted with thiosemicarbazide to yield a solution with $\lambda_{\max .} 265 \mathrm{~m} \mu$ and with $\epsilon_{\max }$ at least as high as $\epsilon_{\max }$ at $273 \mathrm{~m} \mu$ in a parallel reaction with bacilysin itself. With platinum oxide as a catalyst reduction of the carbonyl group may have taken place to a small extent. When the resulting material was allowed to react for $3 \mathrm{hr}$. with thiosemicarbazide the extinction of the solution at $265 \mathrm{~m} \mu$ was only $83 \%$ as high as that of a solution in which the reaction was carried out under similar conditions with material hydrogenated in the presence of palladium on charcoal. With both catalysts the material obtained on hydrogenation was resolved by chromatography on paper in butan-1-ol-acetic acid-water into four ninhydrin-positive spots, with $R_{\text {bacllysin }}$ values of $0.69,0.79,1.04$ and 1.1 respectively. The two spots with the highest $R_{F}$ values were the main ones when the catalyst was palladium on charcoal, but when the catalyst was platinum oxide the spot with $R_{\text {bacllyan }} \mathbf{1} \cdot \mathbf{l}$ was faint and that with $R_{\text {bacllysin }} 0.79$ was relatively intense. The spot with $R_{\text {bacilysin }} 1.04$ absorbed ultraviolet light (Fig. 2).

It thus appeared that the bacilysin molecule could absorb 2 atoms of hydrogen $/ \mathrm{mol}$. in the presence of a catalyst without the reduction of either an olefinic double bond or of a carbonyl group. On the assumption that bacilysin was a dipeptide that has the molecular formula $\mathrm{C}_{12} \mathrm{H}_{18} \mathrm{~N}_{2} \mathrm{O}_{5}$ and contains a ketonic group, one oxygen atom $/ \mathrm{mol}$. remained unaccounted for. The possibility was therefore considered that catalytic reduction involved the hydrogenolysis of an epoxide group:

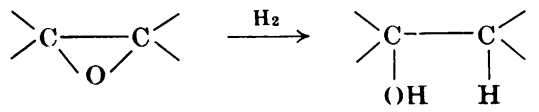

Several other properties of bacilysin were consistent with the presence of an epoxide in the molecule.

1,2-Epoxides are attacked by a variety of nucleophilic reagents (see Winstein \& Henderson, 1950; Parkes \& Isaacs, 1959). The reaction with thiosulphate is accompanied by the liberation of 1 equiv. of alkali (Ross, 1950) and can be followed by titration with acid:

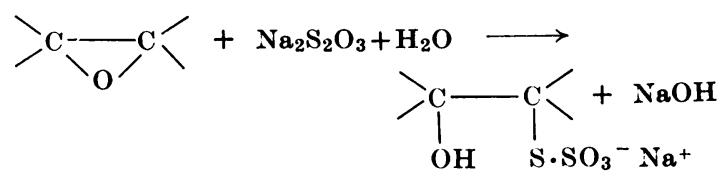

An aqueous solution of sodium thiosulphate (at $\mathrm{pH} 7 \cdot 0)$ was added to a solution of bacilysin $(100 \mu \mathrm{g}$. ml.) in a vessel kept at $37^{\circ}$ and attached to a $\mathrm{pH}$-stat set to maintain the $\mathrm{pH}$ at 7.0 by the automatic addition of $95 \mathrm{mN}$-hydrochloric acid. After $2.5 \mathrm{hr}$. the reaction appeared to have come to an end and the amount of acid added corresponded to the liberation of 0.75 equiv. of alkali/ mol. of bacilysin on the assumption that the molecular weight of the latter was 270. With a preparation of bacilysin whose antibacterial activity was only about $60 \%$ of the purest preparation obtained the apparent liberation of alkali was slightly less than 0.5 equiv./mol. No liberation of alkali was detected when thiosulphate was added to a solution of the material formed on reduction of bacilysin with hydrogen in the presence of palladium on charcoal. The material recovered after the reaction of bacilysin with thiosulphate was subjected to electrophoresis on paper at $\mathrm{pH} 4.5$. Three acidic ninhydrin-positive compounds were detected, which had moved $0.3,0.6$ and 1.3 times respectively as far as aspartic acid towards the anode.

Bacilysin was shown to react with a number of different thiols. Aqueous solutions of the antibiotics (20units/ml.) containing cysteine or 2-mercaptoethanol $(5 \mathrm{mM})$ lost all their antibacterial activity in $75 \mathrm{~min}$. at room temperature at $\mathrm{pH} 7 \cdot 0$. The product of the reaction with 2-mercaptoethanol showed no net change when subjected to electrophoresis on paper at $\mathrm{pH} 4.5$ and an $R_{p}$ value similar to that of bacilysin on chromatography in butan1-ol-acetic acid-water. The reaction with thioglycollic acid, unlike that with 2-mercaptoethanol, was accompanied by the appearance of an absorption band in ultraviolet light $\left(\lambda_{\max .} 301 \mathrm{~m} \mu, E_{1 \mathrm{~cm} .}^{1 \%}\right.$, with a preparation of bacilysin about $60 \%$ pure). The increase in extinction at $301 \mathrm{~m} \mu$ was more rapid at $\mathrm{pH} 8.0$ than at $\mathrm{pH} \mathrm{6.7.} \mathrm{No} \mathrm{H}^{+}$ions appeared

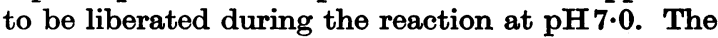
product of the reaction gave a single ninhydrin- 
positive spot after paper chromatography and electrophoresis. It behaved as an acidic compound, migrating towards the anode at $\mathrm{pH} 4 \cdot 5$, showed $R_{\boldsymbol{F}} \mathbf{0 . 4 1}$ in butan-1-ol-acetic acid-water and gave a positive iodine-azide reaction for sulphur (Sjöquist, 1953). The behaviour of this substance on electrophoresis was consistent with the view that it had been formed by the attack on the thiol group of thioglycollic acid on an epoxide group in bacilysin. But its absorption in ultraviolet light indicated that further change had also occurred. Moreover, a number of epoxides react only slowly with glutathione in aqueous solution at $25^{\circ}$ and $\mathrm{pH} 6.5$ unless the reaction is enzyme-catalysed (Boyland \& Williams, 1965). The question therefore arises whether an activated epoxide is present in bacilysin and whether the carbonyl group is involved in the reaction of the latter with thiols.

Epoxides are known to react with pyridine (Eastham, 1952, 1955) and with acetate (Ross, 1950). Such reactions could have been responsible for the loss of activity that was observed to occur during the concentration of aqueous solutions of bacilysin containing pyridine or pyridine-acetate (Rogers et al. 1965). However, the change responsible for this inactivation has not been investigated further.

The group that behaved like an epoxide in bacilysin appeared to be involved in the formation of tyrosine from the molecule in hot $6 \mathrm{~N}$-hydrochloric acid. The products of catalytic reduction of bacilysin yielded little, if any, tyrosine under these conditions, since the corresponding hydrolysates showed no selective absorption in the region of $275 \mathrm{~m} \mu$ (Fig. 5). Reduction with platinum oxide as a catalyst followed by treatment with $6 \mathrm{~N}$ -

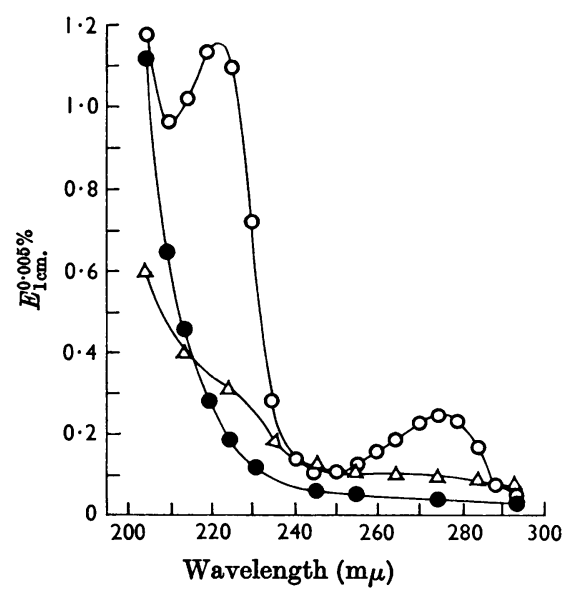

Fig. 5. Ultraviolet spectra of: •, bacilysin (208 units/mg.); $\mathrm{O}$, hydrolysate of bacilysin $\left(6 \mathrm{~N}-\mathrm{HCl}\right.$ at $\left.105^{\circ}\right) ; \Delta$, hydrolysate of products of hydrogenation of bacilysin. hydrochloric acid at $105^{\circ}$ yielded material that was resolved by paper chromatography in butan-1-olacetic acid-water into alanine, a compound that showed an $R_{F}$ value similar to that of tyrosine but gave a violet colour with ninhydrin, and two ninhydrin-positive compounds with $R_{\text {Ala }} 0.60$ and 0.72 respectively (Fig. 2). A similar picture was obtained on paper chromatography of a hydrolysate of material obtained by reduction with palladium on charcoal as a catalyst.

After treatment of bacilysin with $2 \mathrm{~N}$-hydrochloric acid at $105^{\circ}$ for $1 \mathrm{hr}$. very little alanine was revealed by chromatography in butan-1-ol-acetic acidwater, but a ninhydrin-positive compound was present in the hydrolysate that showed an $R_{F}$ value slightly lower than that of tyrosine and strong absorption when the paper was viewed in ultraviolet light (Fig. 2). After hydrolysis for $8 \mathrm{hr}$. paper chromatography indicated that the liberation of alanine was nearly complete, but that the strongly absorbing compound had disappeared and that very little tyrosine had been formed. After $24 \mathrm{hr}$. the amount of tyrosine present was very much less than in comparable experiments in which $6 \mathrm{~N}$ hydrochloric acid was used.

After bacilysin had been kept in $10 \mathrm{mN}$-hydrochloric acid at $37^{\circ}$ for $16 \mathrm{hr}$. only traces of antibacterial activity remained and the solution showed an absorption band with $\lambda_{\max } .243 \mathrm{~m} \mu$. On paper chromatography and electrophoresis the material was found to contain four ninhydrin-positive substances that showed no net change at $\mathrm{pH} 4.5$ and $R_{F}$ values of $0.2,0.37,0.39$ and 0.51 respectively in butan-1-ol-acetic acid-water. After treatment with $10 \mathrm{mN}$-sodium hydroxide under similar conditions a substance was formed with $R_{F} 0 \cdot 24$. On hydrolysis with $6 \mathrm{~N}$-hydrochloric acid at $105^{\circ}$ this gave rise to alanine and a ninhydrin-positive compound with $R_{F} \mathbf{0} \cdot 1$.

The experiments described above were limited by the fact that only small amounts of highly purified bacilysin were available. Since the molecular formula of the substance has not been unequivocally established, since L-alanine and L-tyrosine are the sole degradation products that have been characterized, and since n.m.r. spectra have been determined with partially purified material, no definitive structure for bacilysin can yet be proposed with confidence. Direct proof that the molecule contains a preformed six-carbon ring is lacking. Hydrogenation of phenylalanine, tyrosine and 3,4-dihydroxyphenylalanine with platinum oxide as catalyst yields hexahydrophenylalanine, which shows $R_{\mathrm{Tyr}}$ 1.8 in butan-1-ol-acetic acid-water (see Waser \& Brauchli, 1926). No significant amount of a compound with this $R_{F}$ value was detected in hydro. lysates of the material obtained by hydrogenation of bacilysin. However, several of the properties of 
bacilysin, including the formation from it of tyrosine in hot $6 \mathrm{~N}$-hydrochloric acid, would be understandable if a cyclohexanone grouping carrying an epoxide were present in the molecule. Thus a structure such as (I), or others of a related type including one with a 2,3-epoxy-1-oxo grouping, may provisionally be considered. In these structures the hydroxyl group of tyrosine would originate

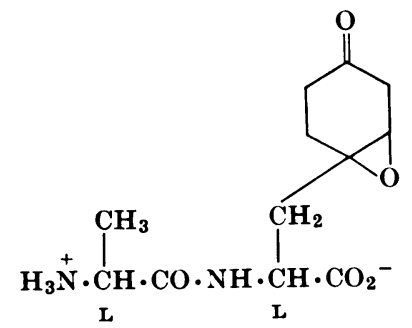

(I)

from enolization of a carbonyl group, and aromatization might result from elimination reactions after the opening of an epoxide. When oxiran rings are opened by reduction, or nucleophilic reagents, the incoming substituent frequently attacks one of the two carbon atoms preferentially and the product consists almost entirely of one compound. However, exceptions to this behaviour are known (Parkes \& Isaacs, 1959) and the situation may be complicated by hydride shifts, eliminations, the formation of diastereoisomers and attack by more than one nucleophile. Thus the finding that more than one product was formed from bacilysin under some of the conditions in which fission of an oxiran ring would occur is not necessarily surprising.

The question arises whether L-tyrosine or Lalanyl-x-tyrosine is an intermediate in the biosynthesis of bacilysin, or whether the formation of this substance involves a diversion from the biosynthetic pathway to tyrosine itself. It also remains to be determined whether the presence of an L-alanine residue is essential for antibacterial activity, or whether a change occurs in the tyrosineyielding residue of the molecule when bacilysin is split and inactivated with leucine aminopeptidase.

\section{EXPERIMENTAL}

Bacilysin preparations. Most of the small-scale experiments were carried out with a preparation of bacilysin which showed an activity of 208 units/mg. and which appeared to be almost homogeneous when studied by paper chromatography and electrophoresis (Rogers et al. 1965). But some experiments were done with less pure material, and the purity of a preparation that was available in sufficient quantity for the determination of n.m.r. spectra was probably not greater than $60 \%$.

Elementary analysis of bacilysin (208 units/mg.) was carried out with a sample dried in vacuo at room temperature (Found: C, 53.20; H, 6.98; N, 10.70; S, 0.30. $\mathrm{C}_{12} \mathrm{H}_{18} \mathrm{O}_{5} \mathrm{~N}_{2}$ requires $\mathrm{C}, 53 \cdot 20 ; \mathrm{H}, 6.71 ; \mathrm{N}, 10 \cdot 40 \%$ ). Halogen was absent. On the assumption that the unhydrated substance had mol.wt. 270 the loss of weight on drying $\left(11.0 \%\right.$ ) corresponded to nearly $2 \mathrm{H}_{2} \mathrm{O} / \mathrm{mol}$.

Nuclear-magnetic-resonance spectra. These were obtained in a Perkin-Elmer R10 nuclear resonance spectrometer in $\mathrm{D}_{2} \mathrm{O}$ at $60 \mathrm{Mcyc}$./sec. Sodium 2,2-dimethyl-2-silopentane5-sulphonate and 2-methylpropan-2-ol, which gave lines at 10 p.p.m. and 8.769 p.p.m. respectively on the $\tau$ scale, were used as internal standards.

Paper chromatography and electrophoresis. Chromatography in butan-1-ol-acetic acid-water and electrophoresis in pyridine-acetate buffer, $\mathrm{pH} 4 \cdot 5$, or in acetic acid-formic acid, $\mathrm{pH} 1 \cdot 8$, were carried out as described by Rogers $e t a l$. (1965). Usually about $50 \mu \mathrm{g}$. of bacilysin, or products derived from this quantity, were applied to the paper. Two-dimensional chromatography of DNP-amino acids was carried out in the 'toluene' and citrate- $\mathrm{HCl}$ systems of Biserte \& Osteux (1951) and of Rovery \& Fabre (1953) respectively.

Electrometric titrations. These were carried out in water at $22-25^{\circ}$ (glass electrode) with an automatic type TTT1 Titrator in conjunction with a type SBR 2/SBU1 Titrograph, made by Radiometer (Copenhagen, Denmark). Samples of bacilysin $(4 \cdot 12 \mathrm{mg}$.) in water $(2.0 \mathrm{ml}$.) were titrated with $117 \mathrm{mN}-\mathrm{NaOH}$ or $93 \mathrm{mN}-\mathrm{HCl}$. Magnetic stirring was used and a stream of $\mathrm{CO}_{2}$-free $\mathrm{N}_{2}$ was passed through the solution. Blank corrections were determined experimentally.

Hydrogenation. This was carried out on a small scale at $25.5^{\circ}$ in the apparatus described by Clauson \& Linborg (1947). Solutions of bacilysin (about $15 \mathrm{mg}$.) in water (2 ml.) were stirred under $\mathrm{H}_{2}$ with $\mathrm{PtO}_{2}$ (4.58mg.) and $10 \% \mathrm{Pd} /$ charcoal (1.44 mg.) respectively. When uptake of $\mathrm{H}_{2}$ ceased, the solution was filtered from the catalyst, the latter washed with water, and the filtrate freeze-dried.

Amino acid analysis. Samples of bacilysin (each about $0.5 \mathrm{mg}$.) were dissolved in $6 \mathrm{~N}-\mathrm{HCl}(1 \mathrm{ml}$.) in Pyrex glass tubes. The latter were sealed under vacuum and placed in an oven at $105^{\circ}$ for $24 \mathrm{hr}$. Despite the removal of $\mathrm{O}_{2}$ (Crestfield, Moore \& Stein, 1963) some humin formation occurred. The hydrolysates were transferred to bottles $(10 \mathrm{ml}$.) and dried in a vacuum desiccator over $\mathrm{NaOH}$ and conc. $\mathrm{H}_{2} \mathrm{SO}_{4}$. The residues were dissolved in $5 \cdot 0 \mathrm{ml}$. volumes of citrate buffer and analysed on an amino acid analyser (from Evans Electroselenium Ltd.) by the procedure of Spackman, Stein \& Moore (1958).

Measurement of the reaction of bacilysin with 1-fluoro-2,4dinitrobenzene. (a) Spectrophotometrically. The procedure was similar to that of Craig, Hausmann \& Weisiger (1953). A solution of bacilysin (2.51 mg., containing $10 \%$ of $\mathrm{H}_{2} \mathrm{O}$ and with an activity of 144 units/mg.) in $1 \%(w / v) \mathrm{NaHCO}_{3}$ $(5.0 \mathrm{ml}$.) was mixed with $5.0 \mathrm{ml}$. of a solution $(0.5 \%, \mathrm{w} / \mathrm{v})$ of fluorodinitrobenzene in ethanol at room temperature. A similar solution, but without bacilysin, was used as a blank. Samples $(100 \mu l$.) were removed from the two solutions at $20 \mathrm{~min}$. intervals, and diluted with $50 \%(\mathrm{v} / \mathrm{v})$ ethanol $(2.9 \mathrm{ml}$.). The extinctions of these solutions were determined at $350 \mathrm{~m} \mu$. The amount of DNP derivative/mol. of bacilysin was $0.75 \mathrm{~mol}$. after $40 \mathrm{~min}$. and $0.97 \mathrm{~mol}$. after $2 \mathrm{hr}$. 
(b) In a pH-stat. A solution of bacilysin (3.22 mg., containing $10 \%$ of $\mathrm{H}_{2} \mathrm{O}$ and with an activity of 208 units/mg.) in water $\left(2.0 \mathrm{ml}\right.$.) was titrated to $\mathrm{pH} 9.0$ under $\mathrm{N}_{2}$ at $23^{\circ}$. Fluorodinitrobenzene solution (50 $\mu \mathrm{l}$.) was added and the $\mathrm{pH}$ maintained at 9.0 by the addition of $93.2 \mathrm{mr}-\mathrm{NaOH}$ with a pH-stat (Radiometer) for $2.5 \mathrm{hr}$. A control solution, containing no bacilysin, was treated similarly. Since the $\mathrm{p} K_{\alpha}$ of the amino group of bacilysin is 8.2 about $13.8 \%$ of this group was in the ionized form. In calculating the extent of the reaction an appropriate correction was therefore made for the $\mathrm{H}+$ ion released by the process:

$$
\mathrm{R} \cdot \stackrel{+}{\mathrm{N}} \mathrm{H}_{3} \rightarrow \mathrm{R} \cdot \mathrm{NH}_{2}+\mathrm{H}^{+}
$$

as well as that produced by the reaction:

$$
\mathrm{R} \cdot \mathrm{NH}_{2}+\mathrm{FDNB} \rightarrow \mathrm{R} \cdot \mathrm{NH} \cdot \mathrm{DNP}+\mathrm{H}^{+}+\mathrm{F}^{-}
$$

where FDNB represents fluorodinitrobenzene. The amount of $93.2 \mathrm{~ms}-\mathrm{NaOH}$ added to the solution containing bacilysin $(0.134 \mathrm{ml}$.) minus that added to the control solution $(0.015 \mathrm{ml}$.) corresponded to the introduction of $0.9 \mathrm{DNP}$ group/mol. of bacilysin.

Isolation and hydrolysis of DNP-bacilysin. The solution obtained after reaction of bacilysin with fluorodinitrobenzene (procedure $a$ ) was evaporated to dryness in vacuo and the residue dissolved in water $(2.0 \mathrm{ml}$.). The resulting solution was extracted with ether $(3 \times 3 \mathrm{ml}$.), the $\mathrm{pH}$ of the aqueous phase lowered to 4.0 and the extraction repeated. One half of the aqueous solution (whose $\mathrm{pH}$ had been raised to $7 \cdot 0$ by the addition of $N$-ethylmorpholine) was then added to a column $(40 \mathrm{~cm} . \times 0.9 \mathrm{~cm}$. diam.) of Sephadex G-25 (200-400 mesh) equilibrated with $50 \mathrm{mN}-N$-ethylmorpholine-acetate buffer, pH7·0. Light was excluded from the column and elution was carried out with the same buffer, fractions $(2 \mathrm{ml}$.) being collected at $30 \mathrm{~min}$. intervals. Water $(2 \mathrm{ml}$.) was added to each fraction and extinctions were measured at $350 \mathrm{~m} \mu$. The DNP derivative emerged from the column in fractions 18-34 as an almost symmetrical band showing a sharp peak at fraction 26. Fractions 22-29 were combined and evaporated to dryness in vacuo.

The resulting DNP-bacilysin $(1.65 \mu$ moles, estimated from measurement of extinction at $350 \mathrm{~m} \mu$ ) was hydrolysed in $6 \mathrm{~N}-\mathrm{HCl}\left(2 \mathrm{ml}\right.$.) for $16 \mathrm{hr}$. at $105^{\circ}$ in a sealed tube in vacuo. The hydrolysate was diluted with water $(12 \mathrm{ml}$.), extracted with ether $(3 \times 10 \mathrm{ml}$.), and the ethereal extract evaporated to dryness. The residue was dissolved in acetone $(25 \mu \mathrm{l}$.) and subjected to two-dimensional chromatography on paper. The area containing the yellow spot corresponding to DNP-alanine was cut out and extracted with $1 \%(w / v)$ $\mathrm{NaHCO}_{3}$ solution ( $15 \mathrm{ml}$.) for $4 \mathrm{hr}$. at room temperature. The extinction of the solution at $350 \mathrm{~m} \mu$ corresponded to the presence of $0.566 \mu$ mole of DNP-alanine on the assumption that the latter showed $\epsilon 17.2 \times 10^{3}$ at $350 \mathrm{~m} \mu$ (Rao \& Sober, 1954), and after a correction (20\%) for destruction during hydrolysis (Porter, 1950).

Reaction with thioglycollic acid. The thioglycollic acid used was distilled (b.p. $115^{\circ} / 15 \mathrm{~min}$.) in vacuo in a stream of $\mathrm{N}_{2}$ and stored at $4^{\circ}$ (White, 1960). Bacilysin (10 mg., $127 \mathrm{units} / \mathrm{mg}$.) was dissolved in water $(1.0 \mathrm{ml}$.) and the $\mathrm{pH}$ of the solution raised to 8.0 by the careful addition of $N$-ethylmorpholine. To this solution was added $0.5 \mathrm{ml}$. of a solution of $N$-ethylmorpholine-acetate buffer, $\mathrm{pH} 8.0$ $(0.2 \mathrm{~N}$ with respect to $N$-ethylmorpholine), and $0.5 \mathrm{ml}$. of a $1 \%(v / v)$ solution of thioglycollate, $\mathrm{pH} 8 \cdot 0$. A control solution was similar except that it contained no bacilysin. Samples $(0.05 \mathrm{ml}$.) were diluted with water $(2.95 \mathrm{ml}$.) and extinctions at $301 \mathrm{~m} \mu$ measured at intervals. The extinction rose to 0.341 in $60 \mathrm{~min}$., to 0.385 in $200 \mathrm{~min}$. and subsequently to a maximum of $\mathbf{0} \cdot \mathbf{4 3 0}$. After evaporation of the solution to dryness in vacuo the residue was examined by electrophoresis and chromatography on paper.

Reaction with sodium thiosulphate. This reaction was carried out at $37^{\circ}$ and followed by use of a pH-stat. A solution of bacilysin ( $0.43 \mathrm{mg}$., 208 units $/ \mathrm{mg}$.) in water (4 ml.) was adjusted to $\mathrm{pH} 7.0$ by the addition of 2 drops of $10 \mathrm{mv}-\mathrm{NaOH}$. A neutral solution $(0.02 \mathrm{ml}$.) of $0.2 \mathrm{M}$ $\mathrm{Na}_{2} \mathrm{~S}_{2} \mathrm{O}_{3}$ was added and the $\mathrm{pH}$ maintained at 7.0 by automatic addition of $9.5 \mathrm{mN}-\mathrm{HCl}$. After $110 \mathrm{~min}$., when $0.107 \mathrm{ml}$. of acid had been added and the rate of addition had become relatively slow, $0.02 \mathrm{ml}$. of the $\mathrm{Na}_{2} \mathrm{~S}_{2} \mathrm{O}_{3}$ solution was added and $8 \mathrm{~min}$. later a further $0.06 \mathrm{ml}$. The second and third addition of $\mathrm{Na}_{2} \mathrm{~S}_{2} \mathrm{O}_{3}$ did not significantly increase the rate of reaction, which terminated within $150 \mathrm{~min}$. with the addition of $0.125 \mathrm{ml}$. of $9.5 \mathrm{~ms}-\mathrm{HCl}$.

A similar experiment was carried out with a larger quantity (3.47 mg.) of a preparation of bacilysin that was not more than $60 \%$ pure. In this case the reaction terminated within $56 \mathrm{~min}$., after the addition of $0.375 \mathrm{ml}$. of $9.5 \mathrm{~ms}-\mathrm{HCl}$. No liberation of alkali occurred when the product of catalytic ( $\mathrm{Pd} /$ charcoal) hydrogenation of bacilysin (208 units/mg.) was treated with $\mathrm{Na}_{2} \mathrm{~S}_{2} \mathrm{O}_{3}$ under similar conditions.

Reaction with thiosemicarbazide. To a solution of bacilysin $(0.7 \mathrm{mg}$., $208 \mathrm{units} / \mathrm{mg}$.) in $0.25 \mathrm{ml}$. of sodium acetate buffer, pH4.5 (50 mM with respect to acetate), were added $0.05 \mathrm{ml}$. of a solution of thiosemicarbazide $(50 \mathrm{~mm})$ in ethanol and $0.2 \mathrm{ml}$. of ethanol. Samples were removed from the mixture at intervals and diluted 100 -fold with $50 \%(\nabla / v)$ ethanol and the extinctions of the resulting solutions were measured at $273 \mathrm{~m} \mu$ against an appropriate blank solution containing acetate buffer and thiosemicarbazide but no bacilysin. The extinction at $273 \mathrm{~m} \mu$ reached its maximum within $2 \mathrm{hr}$.

Enzyme preparations. Leucine aminopeptidase from hog kidney (Hill, Spackman, Brown \& Smith, 1958) was obtained as a freeze-dried powder from Seravac Laboratories (Pty.) Ltd. (Colnbrook, Bucks.). Pronase (Nomoto et al. 1960) was obtained from Calbiochem (Lucerne, Switzerland). Crude D-amino oxidase from hog kidney was obtained from British Drug Houses Ltd. (Poole, Dorset). Crude L-amino acid oxidase, consisting of the dried venom of Crotalus adamanteus, was obtained from Koch-Light Laboratories (Colnbrook, Bucks.).

Hydrolysis with leucine aminopeptidase. The reaction was carried out at $\mathrm{pH} 8.0$ in a buffer containing ammonium acetate $(0.1 \mathrm{M})$ and $\mathrm{MnCl}_{2}(2.5 \mathrm{~mm})$. To a solution of bacilysin $(0.465 \mathrm{mg}$., $208 \mathrm{units} / \mathrm{mg}$.) in $0.25 \mathrm{ml}$. of buffer was added a solution of leucine aminopeptidase $(0.055 \mathrm{mg}$.$) in$ $0.1 \mathrm{ml}$. of buffer previously kept at $37^{\circ}$ for $40 \mathrm{~min}$. to activate the enzyme. The mixture was kept at $37^{\circ}$. Samples (0.1 ml.) were removed after $2 \mathrm{hr}$. and $18 \mathrm{hr}$. respectively and evaporated to dryness in vacuo. The residues were dissolved in water $(50 \mu \mathrm{l}$.) and samples $(5 \mu \mathrm{l}$.) of the resulting solutions were applied to paper for chromatography in butan-1-olacetic acid-water (4:1:4, by vol.). The intensity of the spots on the chromatograms indicated that hydrolysis of the bacilysin was almost complete within $2 \mathrm{hr}$.

In a similar experiment samples $(50 \mu \mathrm{l}$.) were removed after $3 \mathrm{hr}$. and $6 \mathrm{hr}$. respectively from solutions containing 
bacilysin and leucine aminopeptidase and from control solutions containing bacilysin but no enzyme. The samples were diluted to $1 \mathrm{ml}$. in $0.1 \mathrm{M}$-potassium phosphate buffer, pH 7.0, and assayed against Staphylococcus aureus. No significant loss of activity had occurred in the control solution, but no activity was detected in the solution containing leucine aminopeptidase.

Hydrolysis with Pronase. To a solution of bacilysin (0.54 mg., 208 units $/ \mathrm{mg}$.) in $0.1 \mathrm{M}$-ammonium acetate buffer, $\mathrm{pH} 7 \cdot 8$, was added $0.1 \mathrm{ml}$. of a solution of Pronase ( $0.095 \mathrm{mg}$.) in the same buffer. The mixture was kept at $37^{\circ}$ and samples were removed and analysed in the manner used in the experiment with leucine aminopeptidase.

Separation of alanine and tyrosine from a bacilysin hydrolysate. Bacilysin (5mg., 208 units/mg.) was hydrolysed in $1.0 \mathrm{ml}$. of $6 \mathrm{~N}-\mathrm{HCl}$ at $105^{\circ}$ in a sealed tube in vacuo for $24 \mathrm{hr}$. The hydrolysate was evaporated to dryness and the residue dissolved in $0.5 \mathrm{ml}$. of water. The solution was added to a column $(46 \mathrm{~cm} . \times 1 \mathrm{~cm}$. diam.) of Dowex 1 (X8; 100-200 mesh) in the acetate form and elution was carried out with $0.5 \mathrm{~N}$-acetic acid. Fractions (1ml.) were collected every $15 \mathrm{~min}$. Alanine emerged in fractions 12-14 and tyrosine in fractions 25-28. The appropriate fractions were combined and evaporated to dryness to give crystalline residues.

Estimation of the optical configuration of alanine and tyrosine. The following enzyme solutions were used: (1) D-Amino acid oxidase $(10 \mathrm{mg} . / \mathrm{ml}$.) in $0.1 \mathrm{M}$-sodium pyrophosphate buffer, $\mathrm{pH} 8 \cdot 3$, to which a solution of $0.1 \mathrm{~mm}$ FAD $(100 \mu \mathrm{l} . / \mathrm{ml}$. of enzyme solution) was added. (2) L-Amino acid oxidase $(10 \mathrm{mg} . / \mathrm{ml}$.) in $0.2 \mathrm{~N}-N$-ethylmorpholine-acetate buffer, $\mathrm{pH} 7 \cdot 2$. This solution was dialysed in cellophan tubing against the same buffer for $2 \mathrm{hr}$. at $2^{\circ}$ and centrifuged (15 min. at $4000 \mathrm{~g}$ ) to remove suspended material. These solutions were used to distinguish between spots of D- and L-alanine (5-20 $\mathrm{g}$.) on paper by the method of Wagner (1960). They were also used to estimate the amounts of $\mathrm{D}$ - and L-isomers in samples of alanine and tyrosine by measurement of the $\mathrm{NH}_{3}$ formed when oxidation of the amino acid occurred.

To samples (30-100 $\mu$ g.) of amino acid in Pyrex glass tubes $(9 \mathrm{~cm} . \times 1 \cdot 4 \mathrm{~cm}$. diam.) were added samples $(0.2 \mathrm{ml}$.) of the solutions of $\mathrm{D}$ - and L-amino acid oxidase respectively. A further series of tubes contained solutions of the enzymes alone. The tubes were rotated in an almost horizontal position ( $40 \mathrm{rev} . / \mathrm{min}$.) at $37^{\circ}$ for $1.5 \mathrm{hr}$. Water $(0.8 \mathrm{ml}$.) was added to each tube with amino acid and to control tubes. Solutions $\left(0.8 \mathrm{ml}\right.$.) of $\mathrm{NH}_{4} \mathrm{Cl}(1 \cdot 0-0.25 \mathrm{~mm})$ were added to control tubes to provide a standard curve. To each tube were then added $1.5 \mathrm{ml}$. of $\mathrm{N}-\mathrm{NaOH}$ and $1.0 \mathrm{ml}$. of Nessler's solution (prepared as described by Umbreit, Burris \& Stauffer, 1959) and the extinctions of the solutions were measured at $490 \mathrm{~m} \mu$.

In experiments with authentic samples of the $\mathrm{D}$ - and L-isomers of alanine and tyrosine the $\mathrm{NH}_{3}$ estimated to be present after treatment with $\mathrm{D}$ - and L-amino acid oxidase respectively varied between $70 \%$ and $90 \%$ of the theoretical values. The alanine and tyrosine obtained by hydrolysis of bacilysin with $6 \mathrm{~N}-\mathrm{HCl}$ at $105^{\circ}$ yielded approx. $70 \%$ of the theoretical amount of $\mathrm{NH}_{3}$ with L-amino acid oxidase, but less than $10 \%$ of the theoretical amount with D-amino acid oxidase.

Elementary analyses were by Alfred Bernhardt, Mülheim (Ruhr), Germany. We are indebted to the Medical Research
Council for financial assistance, and to Mr Leslie Taylor and Miss Judith Thompson for expert technical assistance. N. L. held a World Health Organisation Fellowship during this work. We thank Dr D. B. Hope and Mrs Christine Walker for analysis of hydrolysates with an amino acid analyser, Mrs R. E. Richards for the determination of n.m.r. spectra and Dr Gordon Lowe for advice on the interpretation of these spectra. We are grateful to Professor Klyne for measurements of rotatory dispersion.

\section{REFERENCES}

Biserte, G. \& Osteux, R. (1951). Bull. Soc. Chim. biol., Paris, 33, 50.

Boyland, E. \& Williams, K. (1965). Biochem. J. 94, 190.

Brown, H. C. \& Ichikawa, K. (1962). J. Amer. chem. Soc. 84, 373.

Brown, H. C., Mead, E. J. \& Rao, B. C. S. (1955). J. Amer. chem. Soc. 77, 6209.

Brown, H. C., Wheeler, O. H. \& Ichikawa, K. (1957a). Tetrahedron, 1, 214.

Brown, H. C., Wheeler, O. H. \& Ichikawa, K. (1957b). Tetrahedron, 1, 221.

Clauson, N. \& Linborg, F. (1947). Acta chem. scand. 1, 884. Craig, L. C., Hausmann, W. \& Weisiger, J. R. (1953). J. biol. Chem. 200, 765.

Crestfield, A. M., Moore, S. \& Stein, W. H. (1963). J. biol. Chem. 238, 622.

Eastham, A. M. (1952). J. chem.Soc. p. 1936.

Eastham, A. M. (1955). J. Amer. chem. Soc. 77, 2182.

Evans, L. K. \& Gillam, A. I. (1943). J. chem. Soc. p. 565.

Fraenkel-Conrat, H., Harris, J. I. \& Levy, A. L. (1955). Meth. biochem. Anal. 2, 260.

Hill, R. L., Spackman, D. H., Brown, D. M. \& Smith, E. L. (1958). Biochem. Prep. 6, 35.

Hirs, C. H. W., Moore, S. \& Stein, W. H. (1954). J. Amer. chem. Soc. 76, 6063.

Kirby, K. S., Knowles, E. \& White, T. (1953). J. Soc. Leath.Tr. Chem. 37, 283.

Lowther, A. G. (1951). Nature, Lond., 167, 767.

Nomoto, M., Narashashi, Y. \& Murakami, M. (1960). J. Biochem., Tokyo, 48, 906.

Parkes, R. E. \& Isaacs, N. S. (1959). Chem. Rev. 59, 737.

Porter, R. R. (1950). Meth. med. Res. 3, 261.

Rao, K. R. \& Sober, E. A. (1954). J. Amer. chem. Soc. 76, 1328.

Rogers, H. J., Newton, G. G. F. \& Abraham, E. P. (1965). Biochem. J. 97, 573.

Ross, W. C. J. (1950). J. chem. Soc. p. 2257.

Rovery, M. \& Fabre, C. (1953). Bull. Soc. Chim. biol., Paris, 35, 541.

Sjöquist, J. (1953). Acta chem. scand. 7, 477.

Spackman, D. H., Stein, W. H. \& Moore, S. (1958). Analyt. Chem. 30, 1190.

Umbreit, W. W., Burris, R. H. \& Stauffer, J. F. (1959). Manometric Techniques, p. 238. Minneapolis: Burgess Publishing Co.

Wagner, M. (1960). Mber. dtsch. Akad. Wiss. Berl. 2, no. 12,751 .

Waser, E. \& Brauchli, E. (1926). Helv. chim. acta, 7, 740.

White, F. H. (1960). J. biol. Chem. 235, 383.

Winstein, S. \& Henderson, R. B. (1950). In Heterocyclic Compounds, vol. 1, chapter 1, p. 1. Ed. by Elderfield, R. C. New York: John Wiley and Sons Inc. 